\title{
MATERIALIDADE E IDENTIDADE: OS SHABTIS DAS ESPOSAS DivinAS DE AMON
}

André Shinity Kawaminami ${ }^{1}$

\section{RESUMO}

As sacerdotisas conhecidas como esposas divinas de Amon foram muito importantes durante alguns períodos da história egípcia. Elas possuíram diversos shabtis, estatuetas que as substituíam nos trabalhos agrícolas do pósmorte. Alguns deles, pertencentes a períodos de dominação estrangeira do Egito, possuíam características do arcaísmo - entendido como uma forma de legitimação dos reis estrangeiros. Levando em consideração os conceitos de materialidade e identidade, este artigo analisará quatro shabtis de esposas divinas das $22^{\mathrm{a}}$ e $25^{\mathrm{a}}$ dinastias para compreender como eles se desprendem de um simples processo de legitimação e como eles são centrais para a compreensão do status social dessas mulheres.

\section{PALAVRAS-CHAVE}

Esposa divina de Amon; shabti; servidor funerário; arcaísmo; materialidade.

\footnotetext{
${ }^{1}$ Mestrando em História Social pela Faculdade de Filosofia, Letras e Ciências Humanas da Universidade de São Paulo (FFLCH/USP), bolsista da Fundação de Amparo à Pesquisa do Estado de São Paulo (FAPESP), processo número 2020/03090-4, membro do Laboratório do Antigo Oriente Próximo da USP (LAOP-USP). E-mail para contato: shinity02@gmail.com.
} 
Mare Nostrum, ano 2021, v. 12, n. 1 .

\section{Introdução}

Os shabtis, pequenas estatuetas que possuíam a função de substituir o seu proprietário nos serviços agrícolas no pós-morte, eram muito presentes nos equipamentos funerários e em contextos votivos do Egito Antigo. Constituídos de materiais diversos, esses servidores poderiam deter inscrições e símbolos que muitas vezes os ligavam ao seu possuidor, trazendo informações sobre sua identidade e sobre as concepções egípcias relacionadas ao universo do pós-morte.

As esposas divinas de Amon, sacerdotisas ligadas ao culto desse deus e à realeza egípcia, também usufruíram dessas estatuetas em seus equipamentos funerários. Muitos de seus shabtis foram de extrema importância para a compreensão do ofício, uma vez que eles nomeiam algumas mulheres que exerceram tal cargo sacerdotal, mulheres essas cujas existências permaneceriam desconhecidas apenas pela análise de outras fontes (Meffre, 2018, p. 134). Inseridas em períodos históricos nos quais ocorreram arcaísmos - isto é, a retomada de características artísticas do passado, como o Terceiro Período Intermediário (1069-664 a.C. $)^{2}$-as estatuetas dessas sacerdotisas também sofreram influências desse resgate artístico na cultura material, o qual muitas vezes foi interpretado primariamente como uma maneira de legitimação ${ }^{3}$ do domínio dos faraós estrangeiros sobre o Egito (Kahl, 2010, p. 5). Isso exclui diversas implicações e outros significados que essas características tiveram na cultura material, tanto como ofusca as diferentes materialidades e agências envolvidas por parte das próprias esposas divinas em relação aos seus shabtis.

Levando em consideração algumas noções de materialidade, agência e identidade egípcias, assim como discussões sobre o arcaísmo da $25^{\text {a }}$ dinastia (c. 747-656 a.C.), este artigo tem como objetivo analisar quatro shabtis pertencentes às esposas divinas de Amon (os de Karomama G Merytmut, Qedmerut, Amenirdis e Shepenupet II) para compreender

\footnotetext{
${ }^{2}$ Três cronologias foram utilizadas neste artigo: a primeira para os períodos históricos e dinastias, proposta por Ian Shaw (2000, pp. 480-489); a segunda cronologia para os reinados dos governantes núbios no Egito, sugerida por Agut \& Moreno-García (2016, p. 538) (pois a datação de Shaw não divide esse período por cada rei. Ademais, os dois autores fizeram a cronologia de sua obra utilizando a de Shaw como base); e, por fim, a terceira foi utilizada para datar o exercício sacerdotal das esposas divinas de Amon citadas ao longo artigo, proposta por Coulon (2018, p. 272). Devido às particularidades e dificuldades relacionadas à datação dos reinados dos governantes núbios no Egito e da especificidade da datação referente às esposas divinas, não foi possível, neste artigo, utilizar apenas uma cronologia.

${ }^{3}$ Como legitimação, entendemos o processo de validação, autenticação e justificação de determinado status ou ação dentro de um sistema social por meio do uso de diferentes meios, como, por exemplo, a utilização de motivos iconográficos específicos, características arcaizantes de uma determinada cultura e titulaturas e prerrogativas de determinados grupos sociais - sobretudo os mais privilegiados.
} 
suas características, gerais e específicas, e como elas estão relacionadas ao arcaísmo núbio. Dessa forma, será possível discutir como seus servidores funerários se descolam de uma simples política de legitimação faraônica e estão relacionados ao processo de crescimento do status e das agências (social, política e religiosa) que essas sacerdotisas possuíram na região de Tebas.

\section{As esposas divinas de Amon e o arcaísmo da $25^{a}$ dinastia}

O ofício sacerdotal de esposa divina de Amon ${ }^{4}$ era ocupado por mulheres da realeza e possuía como principal objetivo servir ao deus Amon, em Tebas. Eram funções das esposas divinas, por exemplo, a realização de diversos rituais, como realizar oferendas aos deuses, apaziguar e estimular as divindades, participar da celebração de festivais e inaugurar monumentos (Ayad, 2009, passim).

Esse cargo foi criado no início do Reino Novo (c. 1550-1069 a.C.) pelo faraó Ahmés (c. 1552-1527 a.C.), que concedeu à sua esposa principal, Ahmés-Nefertari, o título de esposa divina de Amon. Um dos motivos para a criação do ofício foi uma tentativa de inserir no alto da hierarquia sacerdotal de Amon um representante da realeza egípcia para que, assim, o faraó pudesse manter o controle centralizado do Egito recémunificado na época - dado que o sacerdócio de Amon estava se tornando cada vez mais poderoso e influente no Alto Egito (Ayad, 2009, p. 4-6). Durante a 20ª dinastia (c. 11861069 a.C.), o faraó Ramsés VI (c. 1143-1136 a.C.) nomeou sua filha Ísis como esposa divina. É a partir dela que o ofício passa a ser ocupado não mais por rainhas, mas sim por princesas egípcias (Gosselin, 2007, p. 193).

Após o Reino Novo, inicia-se o Terceiro Período Intermediário (c. 1069-664 a.C.), momento marcado pela sua descentralização política. Neste período, houve uma proeminência significativa da autoridade dos altos sacerdotes de Amon (Taylor, 2000, passim), o que gerou conflitos com aqueles que se proclamavam governantes do Egito e buscavam sua unificação. É possível notar também nesse momento um crescimento da importância social e religiosa do ofício de esposa divina quando analisamos a cultura material da região de Tebas.

É nesse contexto que os líbios, após terem migrado ao Egito e desenvolvido uma forte autonomia política, iniciam a $22^{\mathrm{a}}$ dinastia (c. 945-715 a.C.) com o reinado de

\footnotetext{
${ }^{4}$ Uma sacerdotisa desse cargo também poderia ser referenciada como Adoradora Divina e/ou Mão do deus (Ayad, 2009, p. 3-4).
} 
Sheshonq I. Este faraó tentou estabelecer uma política de unificação do Egito, o que envolveu reduzir a independência do culto de Amon e de seus altos sacerdotes. Isso fez com que na $23^{\text {a }}$ dinastia (c. $818-715$ a.C.) o faraó Osorkon III nomeasse sua filha Shepenupet I (c. 765-710 a.C.) como esposa divina de Amon. Para Ayad (2009, p. 15), é a partir dessa dinastia que esse ofício consegue efetivamente alcançar um grande potencial político. Shepenupet I e suas sucessoras foram amplamente representadas em capelas destinadas ao culto de deuses em Karnak, em suas capelas-tumbas em Medinet Habu e no quarteirão residencial das esposas divinas em Naga Malgata - realizando rituais muitas vezes no mesmo patamar que os reis egípcios na iconografia (Ayad, 2009, p. 1).

A partir do reinado de Sheshonq III (825-773 a.C.), muitos governantes locais particularmente no Delta - tornaram-se virtualmente autônomos e se declararam como faraós. Nesse contexto, os reis núbios viram uma oportunidade de dominação das terras egípcias, o que levou o governante de Napata (capital do reino de Kush), Kashta (760751 a.C.), a se interessar pela conquista do Egito. É preciso, no entanto, examinar as motivações por trás desse empreendimento núbio e os ganhos que eles obteriam com o controle de territórios egípcios. Napata possuía acesso a diversas fontes auríferas em seus territórios e contava com rotas de comércio que a ligavam da Arábia do Sul até o Mediterrâneo Oriental, via Mar Vermelho. Assim, Napata estava colocada em um espaçochave de circulação de produtos e pessoas. A conquista do Egito permitiria aos reis núbios a obtenção de recursos egípcios e o controle em seu benefício de toda a parte oeste do espaço onde se efetuava o comércio entre o Mar Vermelho e o Mediterrâneo Oriental (Agut \& Moreno-García, 2016, p. 542-543).

Sob o reinado de Kashta, Napata obteve o controle da Baixa Núbia e do Alto Egito. O início da conquista desse pode ser entendido como a aceitação, por parte do sacerdócio de Amon em Tebas, em receber sua filha e princesa Amenirdis (c. 710-678 a.C.) como sucessora da esposa divina de Amon líbia, Shepenupet I. Como colocado anteriormente, somente princesas reais passaram a poder ocupar esse ofício. Para Agut e Moreno-García, o fato de o sacerdócio de Amon ter aceitado Amenirdis como sucessora ao cargo de esposa divina poderia ter dois significados: o primeiro é o de que os sacerdotes do culto desse deus reconheciam formalmente o rei núbio como faraó; por sua vez, o segundo é o de que Kashta, com a nomeação de sua filha ao cargo, passou a dispor de um ponto de influência e contato na hierarquia sacerdotal de Amon, a instituição religiosa mais importante do Alto Egito. Além disso, os faraós núbios agora tinham também acesso aos 
diversos bens e propriedades relacionadas ao ofício de esposa divina e ao sacerdócio de Amon (Agut \& Moreno-García, 2016, p. 545).

Depois de Kashta, seu filho e sucessor Piankhy (c. 747-716 a.C.) deu prosseguimento a investida de seu pai. A conquista do restante do Egito é concluída pelo irmão de Piankhy, Shabaqo (c. 716-702 a.C.). Assim, o Egito finalmente é anexado aos domínios dos reis núbios e inicia-se a $25^{\text {a }}$ dinastia (Taylor, 2000, p. 331). Uma das principais características dessa dinastia é o arcaísmo que foi empregado pelos faraós núbios na cultura material egípcia. No contexto deste artigo, consideramos como arcaísmo um movimento de retomada de modelos, conceitos, estilos e símbolos de períodos anteriores da história egípcia nos campos da arte, religião, língua e escrita. O arcaísmo era, em essência, um dos mecanismos utilizados para se recorrer ao passado sem buscar criar cópias idênticas de objetos antigos (Kahl, 2010, p. 1). Esse movimento não deve ser compreendido como uma "exaustão criativa" dos egípcios antigos nem como um reuso sem propósitos específicos (Török, 1997, p. 189-190). O arcaísmo pode ser detectado nas fontes egípcias desde o Reino Antigo, alcançando pontos de culminação em determinados períodos históricos (como durante as $18^{\mathrm{a}}, 22^{\mathrm{a}}, 25^{\mathrm{a}}$ e $26^{\mathrm{a}}$ dinastias, por exemplo) e poderia ser empregado por indivíduos da esfera da realeza ou não (principalmente membros da elite ligados às esferas oficiais e sacerdotais) (Kahl, 2010, pp. 2-6).

Durante a $25^{\text {a }}$ dinastia, é possível encontrar diversas características arcaizantes na cultura material do período. Há objetos que possuem estilos e detalhes de obras dos Reinos Antigo, Médio e Novo, principalmente nas esculturas e nos relevos. Para Török, a Egiptologia tratou a desintegração política do Egito no Terceiro Período Intermediário como momentos de decomposição de uma estrutura sociocultural centralizada - o que gerou crises políticas e decadência de valores. Nesse contexto, os faraós núbios, com o objetivo de reunificar o Egito e legitimar o seu poder, buscaram elementos artísticos do passado dessa sociedade para reproduzi-los na produção material e artística e, com isso, restaurarem o Egito à sua glória antiga. Portanto, o arcaísmo passou a ser majoritariamente compreendido como uma forma de legitimação e propaganda faraônicas, a qual ocorria principalmente em períodos de grandes mudanças estruturais e políticas (Török, 1997, p. 190-191).

De fato, é possível pensar no arcaísmo como um mecanismo de legitimação política que foi empregado por diferentes dinastias. Entretanto, é preciso ter cautela quanto a uma definição rígida e limitadora do arcaísmo, uma vez que o resgate de 
características do passado nem sempre estava apenas relacionado a uma maneira de legitimar um domínio político em contextos de descentralização e governos de reis estrangeiros. É o caso, por exemplo, de alguns shabtis das esposas divinas de Amon, notadamente o de algumas dessas sacerdotisas do período da $25^{\mathrm{a}}$ dinastia, as quais, assim como os faraós, eram núbias. Para analisá-los, é preciso antes compreender o que eram essas estatuetas e suas características gerais.

\section{Shabtis: os servidores funerários egípcios}

Os servidores funerários, conhecidos como shabtis, shawabtis ou ushabtis ${ }^{5}$, são pequenas estatuetas (chegando a no máximo $45 \mathrm{~cm}$ de altura) que eram destinadas a substituir um indivíduo no trabalho nos campos do pós-morte. Esses objetos apresentavam variações em sua quantidade por indivíduo, material, forma, estilo e inscrições de acordo com as concepções egípcias de cada período histórico. Os shabtis eram muito presentes em boa parte das tumbas, principalmente as da elite e da realeza, e eram colocados geralmente próximos do corpo do falecido na câmara funerária (no solo, em caixas ou em nichos). Essas estatuetas são muito importantes para compreendermos diversos aspectos da visão religiosa, cultural e social do Egito Antigo.

\subsection{Breve Panorama Histórico do Desenvolvimento dos Shabtis}

Os shabtis surgem durante o Reino Médio (c. 2055-1650 a.C.), sendo os exemplares mais comuns dessa época constituídos em madeira ou pedra e retratados como trabalhadores do campo. Neste período, o qual sucede um momento de convulsões sociais e políticas no Egito conhecido como Primeiro Período Intermediário (c. 2160-2055 a.C.), a produção dessas estatuetas ocorreu provavelmente por conta do saque de tumbas. Para alguns autores, isso estaria ligado à possibilidade de garantir a preservação da integridade do falecido no pós-morte para além de sua múmia ao acrescentar em seu equipamento funerário mais dessas estatuetas servidoras (Gama, 2008, p. 25).

\footnotetext{
${ }^{5}$ Não há um consenso sobre a definição do significado dessas palavras. A variação de sua escrita ocorria de acordo com cada período histórico, com seu significado podendo alterar-se conforme o uso de diferentes determinativos. De maneira geral, a etimologia dessas palavras está relacionada ao material em que essas estatuetas eram feitas, suas funções no pós-morte como substitutos do falecido e provedores de alimentos (Gama, 2008, p. 35). No caso deste artigo, utilizaremos o termo shabti, que aparece no Reino Novo e foi utilizado até o Período Ptolomaico (332-30 a.C.).
} 
Isto pode ser corroborado pelo fato de que os shabtis dessa época eram majoritariamente representados na forma de múmias, uma inovação do período que os associava ao falecido e ao deus Osíris. Ao deus Osíris, senhor do mundo dos mortos, ligado à regeneração da vida e ao ciclo agrário egípcio (Pinch, 2002, pp. 178-180), estava atrelada a concepção do mundo pós-morte como uma espécie de imagem semelhante à vida cotidiana - o que implicaria também na necessidade do trabalho agrícola para a alimentação e pagamento de tributos aos deuses. De maneira geral, as estatuetas, que poderiam portar ou não insígnias, não eram encontradas em grandes quantidades nas tumbas, sendo o número mais comum para a época o de um shabti por falecido. Quando portavam inscrições - nome e títulos do indivíduo e/ou o Capítulo 6 do Livro dos Mortos, por exemplo -, elas identificavam o proprietário e retratavam essencialmente os serviços agrícolas a serem executados pela estatueta no lugar do morto.

A maior parte dos shabtis encontrados e datados deste período era feita em pedra - como granito e xisto -, material fisicamente resistente e que permitia uma durabilidade para as estatuetas que fossem dispostas próximas de estelas ou em nichos externos à tumba, de modo que não se desgastavam rapidamente (Gama, 2008, p. 84-85). Assim, um shabti poderia conservar magicamente a integridade corporal do falecido e prestar serviços para seu proprietário no pós-morte.

Durante o Reino Novo, essas estatuetas passaram por novas mudanças: além do formato mumiforme, surgem os shabtis contramestres (também conhecidos como mer $m r$ ou $m D-$, mestre de dez), que serviam para supervisionar uma dezena de estatuetas servidoras e que trajavam vestimentas do cotidiano da época, à imagem do proprietário (Meffre, 2018, p. 134). Outra inovação desse período foi o surgimento de representações de instrumentos agrícolas nos shabtis: os mais frequentes eram a picareta e a enxada egípcias, seguradas pelas mãos do servidor funerário. Alguns possuíam também, em suas costas, uma espécie de saco suspenso por uma ou duas cordas que servia como um recipiente para grãos ou para a retirada de areia (trazida pelos ventos) dos campos de cultivo. Portanto, podemos compreender que essas ferramentas e objetos reforçam a ideia e a associação desses servidores com o universo agrícola do pós-morte (Gama, 2008, p. 53-54) e a de substituição do morto nesse tipo de serviço. Quanto aos shabtis contramestres, os instrumentos que eles portavam poderiam ser um bastão e/ou um açoite (nunca ferramentas agrícolas), usados na inspeção das estatuetas servidoras.

Assim, os servidores funerários passaram por uma nova complexificação simbólica. Segundo Meffre (2018, p. 140), essas estatuetas mantinham uma ambivalência 
quanto a sua forma e estatuto: elas eram feitas à imagem do indivíduo falecido quando no formato mumiforme e à imagem do proprietário em vida quando o shabti era retratado com roupas do cotidiano, como um contramestre.

Durante a $19^{\text {a }}$ dinastia (c. 1295-1186 a.C.), o uso de shabtis no contexto funerário amplia-se para outras camadas sociais: é possível encontrar a partir dessa dinastia estatuetas feitas em modelos simples de terracota, muitas vezes sem inscrições, nas tumbas de indivíduos não pertencentes à realeza e elite. Também cresce o costume de depositar os shabtis em pequenas urnas específicas criadas para guardá-los (Gama, 2008, p. 50).

No início do Terceiro Período Intermediário, os shabtis passam por novas alterações. De maneira geral, eles eram caracterizados por uma simplificação em relação aos modelos anteriores, apresentando muitas vezes apenas o nome e um dos títulos do proprietário. Ocorre uma uniformização quanto ao material dos servidores, sendo constituídos nesse período principalmente em faiança egípcia ou terracota, uma vez que os de madeira e pedra tornam-se raros. Para Schneider (1977, p. 319-320), é nesse momento que o caráter dessas estatuetas muda de imagem substituta do morto para o estatuto de servos despersonalizados e dissociados da imagem de seu proprietário. $\mathrm{O}$ número ideal de shabtis por pessoa passa a ser o de $401^{6}$ e inicia-se um processo de padronização da forma, material e texto das estatuetas. Entretanto, há momentos e casos de exceção dessa nova tendência. Houve a retomada da fabricação de shabtis, em pedras duras e escuras, para os reis, as esposas divinas e alguns altos oficiais de Tebas sob o governo dos faraós núbios da $25^{\mathrm{a}}$ dinastia, o que, por exemplo, foi resultado de uma política arcaizante (Schneider, 1977, p. 234). Também nesse período aparecem servidores funerários mais robustos, feitos em serpentina.

Uma padronização mais rígida dessas estatuetas pode ser observada no Período Tardio (664-332 a.C.): elas possuem agora apenas o formato de múmias, as inscrições aparecem em linhas horizontais e a maioria delas porta instrumentos agrícolas. Além disso, os shabtis adquirem uma base retangular e um pilar dorsal, apresentando menos variações do que nos períodos anteriores. Com isso, o Período Tardio marca a última

\footnotetext{
${ }^{6}$ Cada estatueta desse conjunto de 401 shabtis representava um dia do ano egípcio e, para cada dezena, havia um contramestre responsável por supervisioná-los. De acordo com o calendário egípcio, um ano possuía 12 meses de 30 dias, acrescentando-se 5 dias epagômenos. No total, temos, portanto, 365 shabtis trabalhadores e 36 contramestres. Entretanto, é necessário termos em mente que essa quantidade por indivíduo era idealizada, não correspondendo a que era encontrada na maior parte das tumbas escavadas dado que muitas delas foram saqueadas, implicando na destruição, dispersão ou desaparecimento de muitos shabtis (Meffre, 2018, p. 134).
} 
mudança na estrutura desses servidores, os quais caem em desuso no final do Período Ptolomaico (c. 332-30 a.C.) (Gama, 2008, p. 67-68).

\subsection{Material, Cores e Inscrições}

Para os objetivos deste artigo, é importante nos debruçarmos sobre algumas características dos shabtis - principalmente os do Terceiro Período Intermediário -, como seu material de composição, suas cores e inscrições.

Quanto aos materiais das estatuetas funerárias, nos interessa neste artigo principalmente dois deles: a faiança egípcia e a pedra. O primeiro era um tipo de cerâmica egípcia, a qual não era feita de barro, mas sim de areia e quartzo triturado, e que se assemelhava a um tipo de louça produzida na cidade de Faenza, na Itália - daí a atribuição do nome de "faiança" egípcia. Sua composição poderia variar de acordo com o período histórico ou habilidade do produtor (Gama, 2008, p. 86).

Para os egípcios, este tipo de cerâmica era conhecido como tehenet (THnt, "brilhar", "brilhante"), em razão do efeito visual causado por sua composição, o que resultava em uma espécie de vitrificação. Sua existência é atestada desde o Período PréDinástico (c. 5300-3000 a.C.), mas sua produção começa a ser difundida a partir do Reino Médio. Durante o Reino Novo, os objetos feitos em faiança egípcia adquirem novas cores e tonalidades, como o azul escuro, o verde e o preto, os quais eram resultados de combinações de óxidos diversos (Nicholson, 2005, p. 352-353).

Quanto ao significado da faiança para os egípcios antigos, não possuímos muitas fontes que tratam diretamente sobre isso. Sabemos que esse material muitas vezes era entendido como um substituto de pedras semipreciosas, e grande parte dos amuletos eram compostos por ele. Sua presença nos objetos funerários era muito comum, como é o caso da maioria dos shabtis (Nicholson, 2001, p. 495). Assim, é possível associar o seu uso como uma forma de substituir a composição de um artefato em pedra semipreciosa, possibilitando uma maior durabilidade e um certo prestígio social - ainda que não saibamos como precisá-lo especificamente.

Sobre a pedra, este material pode ter sido utilizado na confecção de shabtis principalmente por conta de sua resistência, aumentando-se a preservação física da estatueta e relacionando-se à eternidade pressuposta nos seus trabalhos no pós-morte. Diferentes pedras e rochas possuíam significados e prestígios distintos. Entretanto, há uma dificuldade para compreendermos quais eram eles e suas implicações na concepção 
egípcia antiga, dado que há poucos registros que nos informam sobre isso. Ademais, nem sempre é possível identificar com precisão o tipo de pedra ou rocha de um objeto, seja por conta de seu estado de preservação ou mesmo por outras características artísticas, como, por exemplo, uma pintura que recobre o material base (Baines, 2007, p. 272). Assim, podemos compreender o uso de shabtis de pedras como uma forma de garantir a maior durabilidade do servidor e, portanto, preservar sua eficácia, tanto material como mágica, em suas funções no pós-morte.

De maneira geral, as cores dos shabtis são, assim como seus materiais, importantes para datá-los, pois em cada período há uma certa frequência de alguns tipos de cores. Sua escolha era regida por sistemas de padrões e seus usos carregavam diferentes significados simbólicos (Robins, 2001, p. 291). No caso das estatuetas selecionadas para o artigo, o predomínio era de servidores de faiança normalmente em um azul escuro e brilhante. Quanto aos shabtis feitos em pedra, a cor mais presente era a preta.

Para os egípcios antigos, o azul era associado ao céu noturno e às águas primordiais, das quais o sol nascia renovado a cada dia. Durante o Reino Novo, AmonRá passou a ser retratado com a pele azul, simbolizando seu papel como deus criador, o qual surgiu das águas primordiais e que delas obtinha sua regeneração noturna. Os itens que compunham equipamentos funerários feitos de faiança azul, portanto, estavam relacionados principalmente à ideia de regeneração e ao deus Amon (Robins, 2001, p. 292).

A cor preta carregava conotações parecidas com a azul, sendo a principal delas a ideia de regeneração, ligada principalmente à fertilidade, associando-se assim ao deus Osíris e ao mundo dos mortos. Segundo Robins (2001, p. 291), pedras pretas eram frequentemente utilizadas em estátuas e outros objetos para evocar essas características de Osíris e do pós-morte.

Ao analisarmos os significados de ambas as cores citadas, é possível compreendêlas como uma associação ao deus Osíris, seus atributos e seus domínios no Além. As estatuetas de servidores em azul e preto recebiam um status semelhante ao do falecido que adentrava no mundo pós-morte e incorporavam a renovação do ciclo agrícola e da eternidade ligadas a Osíris (Gama, 2008, p. 94). Assim, a escolha do material e das cores dos shabtis não era neutra, formando um conjunto de rede de significados e símbolos da cultura egípcia para garantir a eficácia mágica e religiosa das funções desses artefatos. $\mathrm{O}$ mesmo vale para os textos inscritos nos shabtis. 
Como colocado anteriormente, quando os servidores funerários possuíam inscrições elas poderiam apresentar o nome do proprietário, alguns de seus títulos, o nome de um parente e variações do Capítulo 6 do Livro dos Mortos. A questão de representar o nome na cultura egípcia era algo muito importante, pois era uma das formas de garantir magicamente a integridade da existência do indivíduo durante sua vida e após sua morte, uma vez que os egípcios consideravam o esquecimento ou a destruição material de seu nome como a eliminação de sua existência (Doxey, 2001, p. 490). O nome de um falecido era inscrito em boa parte de seus objetos funerários como uma forma de assegurar também sua identidade e de que as provisões, oferendas e representações em sua tumba fossem direcionadas apropriadamente para si (Wendrich, 2010, p. 206).

Desse modo, ter o nome inscrito nos shabtis pode ser considerado como mais uma das formas de preservação do proprietário no pós-morte. Sobre o Capítulo 6 do Livro dos Mortos, este texto instruía, essencialmente, o trabalho dos shabtis nos campos agrícolas no lugar do morto e ele variava ligeiramente conforme a época de confecção das estatuetas.

\section{Os Shabtis das Esposas Divinas de Amon}

As esposas divinas de Amon também possuíram shabtis como parte de seus equipamentos funerários. Para além da datação e sobre as concepções religiosas de cada período, essas estatuetas nos permitem conhecer algumas dessas sacerdotisas de Amon, as quais não conheceríamos por meio de outras fontes. É o caso, por exemplo, da esposa divina Mehytemusekhet (c. 940-900 a.C.): seus servidores funerários são os únicos vestígios materiais aos quais hoje possuímos acesso, que nos informam de sua existência, e que, por fim, nos permitem situá-la historicamente no Terceiro Período Intermediário.

Este artigo analisa quatro shabtis - três trabalhadores mumiformes e um contramestre - de esposas divinas de Amon desse período, sendo elas: Karomama G Merytmut, Qedmerut, Amenirdis e Shepenupet II $^{7}$. A estatueta de Karomama G Merytmut (c. 850-810 a.C.), esposa divina da $22^{a}$ dinastia durante os reinados de Harsiese, Osorkon II e Takelot II (865-810 a.C.), provém da Necrópole Tebana, provavelmente do Cemitério do Ramesseum, e foi feita em faiança. Atualmente possui uma cor verde oliva,

\footnotetext{
${ }^{7}$ A escolha desses quatros shabtis foi feita com base na disponibilidade de suas imagens e inscrições em alta qualidade. Há outras estatuetas desse tipo de esposas divinas, apesar de espalhadas em diferentes coleções de museus e nem sempre bem catalogadas com detalhe.
} 
mas anteriormente possuía a cor azul com detalhes em preto. Situado hoje no Museu do Louvre (E 5335), o shabti de contramestre possui 14,4 cm de altura, 4,7 cm de largura e $3,3 \mathrm{~cm}$ de espessura. Ele utiliza uma peruca com um uraeus $^{8}$ quebrado e uma faixa amarrada sobre a nuca. A estatueta é retratada com o braço direito sobre o peito, segurando um chicote, e está vestida com uma túnica com a faixa sobre o quadril. Em suas costas, encontra-se um saco de grãos. Sobre a túnica e as pernas do contramestre temos uma inscrição com o nome de Karomama dentro de um cartucho: "A Osíris, a Adoradora do deus Amon, Karomama, Amada de Mut" (Gombert-Meurice \& Payraudeau, 2018, p. 284, tradução nossa ${ }^{9}$ ).

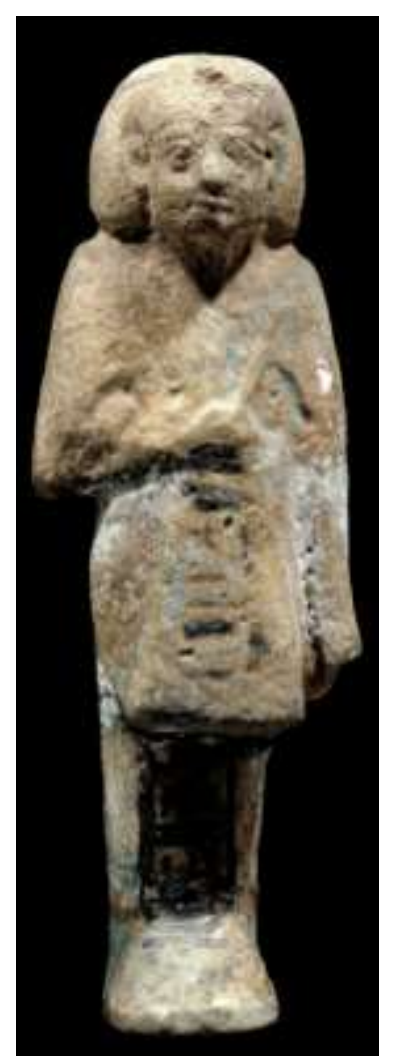

Figura 1. Shabti contramestre de Karomama G Merytmut (Exposição Servir les dieux d'Égypte, Museu de Grénoble, França, 2018. Cat. 136)

Fonte: Gombert-Meurice \& Payraudeau, 2018, p. 284

\footnotetext{
${ }^{8} \mathrm{O}$ uraeus era uma das insígnias faraônicas, portado na frente de coroas ou adornos que eram colocados sobre a cabeça. Ele era composto por uma cobra e um abutre, por vezes apenas pelo primeiro animal. A cobra representava a deusa Wadjet, protetora do Baixo Egito, enquanto o abutre representava a deusa Nekhebet, que protegia o Alto Egito. De maneira geral, era entendido que o uraeus era uma das formas de defesa de seu portador contra inimigos do Egito (Bunson, 2012, p. 455). Ademais, esse símbolo também era portado por algumas rainhas na iconografia egípcia.

${ }^{9}$ As traduções das inscrições dos shabtis para o português foram feitas a partir das traduções para a língua francesa propostas por Gombert-Meurice \& Payraudeau (2018) e Bovot (2003), baseando-se também na consulta e análise dos hieróglifos e das transliterações das mesmas inscrições fornecidas por Bovot (2003).
} 
Proveniente do mesmo local que o shabti de Karomama G Merytmut, é também feito em faiança. Nele temos representado um servidor funerário da sacerdotisa Qedmerut (c. 800-?), datado da $22^{\mathrm{a}}$ dinastia. Atualmente a estatueta faz parte de uma coleção particular (coleção Dr. J. P., no 353) e possui 9,8 cm de altura. Em formato mumiforme, o servidor utiliza uma peruca tripartite e um uraeus modelado em sua testa. É possível ver alguns resquícios de tinta, os quais indicam uma faixa amarrada atrás de sua cabeça, de seus olhos e das sobrancelhas em seu rosto pouco modelado. Seus braços estão cruzados sobre o peito, em suas mãos encontram-se duas enxadas, e atrás da estatueta podemos ver um saco de grãos pintado. Quanto às inscrições, há uma coluna de hieróglifos sobre sua perna: "Osíris, a Senhora das Duas Terras, a Adoradora Divina, Qedmerut" (Gombert-Meurice \& Payraudeau, 2018, p. 285, tradução nossa). Esta esposa divina, assim como Mehytemusekhet, só é conhecida por meio de seus shabtis.

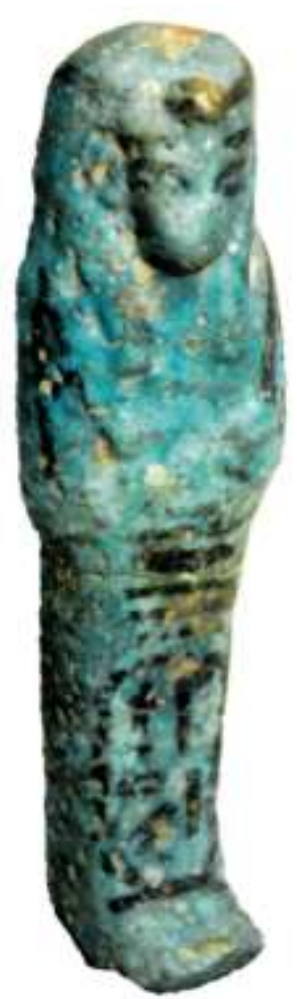

Figura 2. Shabti de Qedmerut (Exposição Servir les dieux d'Égypte, Museu de Grénoble, França, 2018. Cat. 137)

Fonte: Gombert-Meurice \& Payraudeau, 2018, p. 285

A estatueta funerária de Amenirdis (c. 710-678 a.C.), sacerdotisa núbia da 25a dinastia, de proveniência desconhecida (provavelmente advinda de Medinet Habu), encontra-se hoje no Museu do Louvre (N 647). Feito em pedra escura na tonalidade preta 
Mare Nostrum, ano 2021, v. 12, n. 1 .

(provavelmente em serpentina), o shabti possui $21 \mathrm{~cm}$ de altura (um tamanho grande e excepcional), 6,4 $\mathrm{cm}$ de largura e 4,26 cm de espessura. O servidor mumiforme utiliza uma peruca tripartite com um uraeus, seus braços estão cruzados e não há a presença de ferramentas agrícolas. Apesar de estar levemente danificado, sua inscrição em oito linhas é legível e trata-se do Capítulo 6 do Livro dos Mortos (uma versão que data da $13^{\mathrm{a}}$ dinastia):

Linha 1: Ó, shabtis, se contarmos a esposa divina [...]

Linha 2: Amenirdis, a seu dever (de mulher)! A obrigação será infligida a eles [...]

Linha 3: Como a Esposa Divina em sua tarefa, aqui ela está

Linha 4: tu dirás, se o contarmos para executar (sic) a todo momento

Linha 5: (para) fazer aqui (no mundo dos mortos), para retornar os campos

Linha 6: para (tornar férteis) os bancos, para transportar

Linha 7: a areia do oeste (em direção à)

Linha 8: leste, eu aqui, tu dirás. (Bovot, 2003, p. 337, tradução nossa).

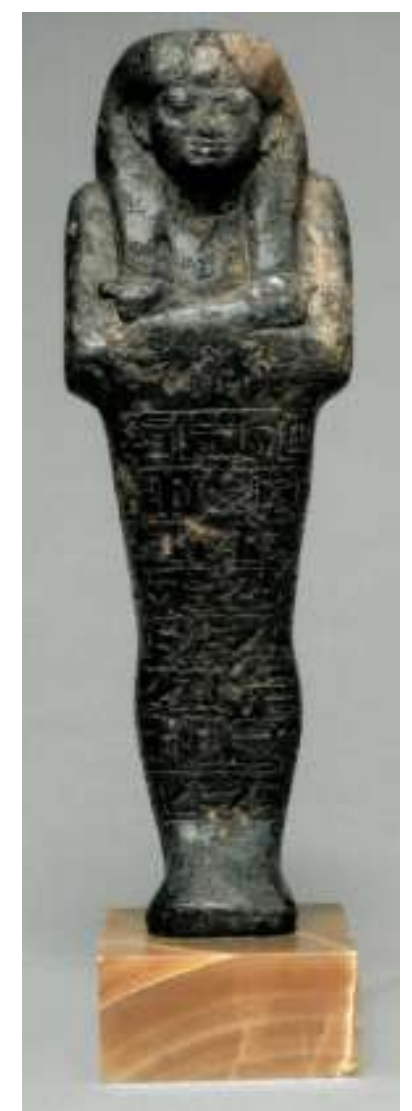

Figura 3. Shabti de Amenirdis (Exposição Servir les dieux d'Égypte, Museu de Grénoble, França, 2018. Cat. 139)

Fonte: Gombert-Meurice \& Payraudeau, 2018, p. 287 
É possível notar que a versão do texto data do Reino Médio e que, além disso, o shabti possui um sorriso em sua face, uma característica de algumas estatuetas do Reino Novo (Gombert-Meurice \& Payraudeau, 2018, p. 287). Esses dois elementos fazem parte do arcaísmo dos faraós núbios, como citado anteriormente.

Por fim, o último shabti selecionado é o de Shepenupet II (c. 678-639 a.C.), outra esposa divina núbia da $25^{\mathrm{a}}$ dinastia. Essa estatueta provavelmente advém de Medinet Habu e está localizada atualmente no Museu do Louvre (E 11159). Feito em pedra dura e preta (que se assemelha à serpentina), com 10,67 cm de altura, 6,83 cm de largura e 4,7 $\mathrm{cm}$ de espessura, este servidor funerário mumiforme, quebrado no meio, utiliza uma peruca tripartite ornamentada com um uraeus sobre a testa e um modius acima da peruca - espécie de suporte sobre o qual eram colocados adornos, como uma coroa. Esse shabti tem seus braços cruzados e não porta qualquer tipo de ferramenta (Gombert-Meurice \& Payraudeau, 2018, p. 286). Há algumas inscrições abaixo de seus braços, que se encerram onde o servidor está quebrado, e em suas costas, que trazem alguns de seus títulos e uma versão do Capítulo 6 do Livro dos Mortos (bastante fragmentada por conta do estado da estatueta):

Linha 1: A Iluminada, Osíris, a Adoradora Divina, Shepenupet, Justificada, Filha do rei Piankhy. Ela diz: Ó,

Linha 2: shabtis, se contarmos a Adoradora Divina Shepenupet, Justificada, para fazer [...] [verso]

Linha 3: [...] do oeste (ou do leste) e vice versa ${ }^{10}$ [...]. (Bovot, 2003, p. 341, tradução nossa).

Segundo Gombert-Meurice e Payraudeau (2018, p. 286), este shabti de Shepenupet II provavelmente integrava sua capela-tumba em Medinet Habu, pois lá foram encontradas outras de suas estatuetas funerárias. Elas eram divididas em dois grupos: o primeiro com o tamanho tradicional pequeno, em faiança siliciosa verde, e o segundo com os shabtis de pedra escura de tamanho alto.

\footnotetext{
${ }^{10}$ Uma referência ao transporte da areia retirada dos campos.
} 


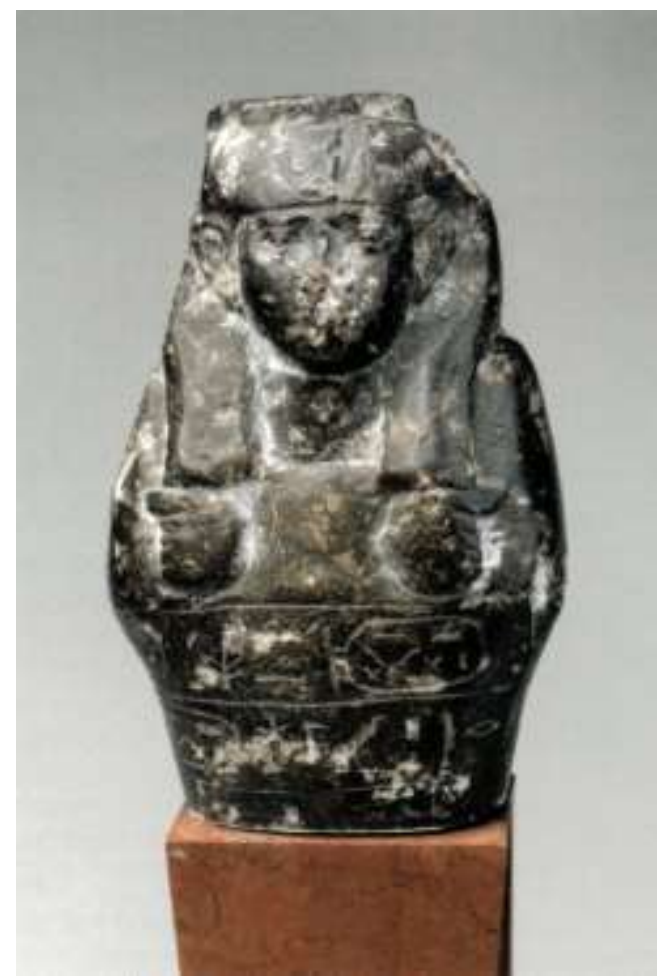

Figura 4. Shabti de Shepenupet II (Exposição Servir les dieux d'Égypte, Museu de Grénoble, França, 2018. Cat. 138)

Fonte: Gombert-Meurice \& Payraudeau, 2018, p. 286

Para analisarmos apropriadamente as estatuetas selecionadas tendo em vista os objetivos deste artigo, é necessário compreendê-las contextualmente nas esferas sociais, culturais e religiosas egípcias, o que implica as noções de materialidade, identidade, cópia e agência da cultura material funerária.

\section{Materialidade, Agência e Identidade}

A cultura egípcia possuía noções próprias sobre sua produção material funerária e as suas diferentes relações com ela. Nesse contexto, a teoria antropológica da arte de Gell nos auxilia na definição de uma agência da cultura material egípcia: cada objeto possuía uma agência própria, isto é, uma capacidade de agir sobre alguém e/ou algo que não apenas era determinada por seu criador ou possuidor, mas também pelo inverso. Assim, um artefato poderia agir sobre seu proprietário, em uma relação complexa de causa e efeito que envolvia outras esferas sociais e diferentes indivíduos e objetos (Gell, 2018, pp. 45-46). Desse modo, os equipamentos funerários egípcios não devem ser considerados como expressões reflexivas e passivas das intenções de seus criadores, mas 
também como agentes e portadores de diferentes capacidades de exercer influência e significado sobre algo.

A partir disso, podemos compreender algumas das diversas maneiras dos egípcios antigos de se relacionarem com sua cultura material - o que envolve a noção de materialidade. Essa pode ser definida como o engajamento físico de um indivíduo e/ou sociedade com o mundo, uma relação em que a cultura é constituída e moldada em um sentido corporificado e externo (Meskell, 2004, p. 11). A materialidade está ligada aos domínios de produção, troca, consumo e descarte, assim como questões de mimesis, simulacros e agência entre indivíduos e objetos (Meskell, 2004, p. 14). Para compreendêla, devemos localizá-la em contextos históricos e materiais de uma dada cultura específica, na medida em que as relações de uma sociedade com seus objetos não são estáticas e variam conforme o tempo e cultura. Em suma, a materialidade é um conjunto de relações entre pessoas e sua produção material.

No caso do Egito Antigo nos interessa principalmente a produção de objetos que de alguma forma estavam relacionados ao status e identidade de um indivíduo falecido. Segundo Meskell (2004, p. 7), a cultura egípcia possuía uma grande ênfase na criação e representação de artefatos que estavam ligados a uma pessoa por meio de conceitos sociorreligiosos. Os egípcios possuíam uma ideia específica do que podemos chamar de duplicação e dualidade (ordem e caos, Alto e Baixo Egito, etc), o que tornava muitas vezes o ato de criar objetos, relevos e monumentos um processo de externalização e cópia de uma pessoa ou um deus, por exemplo, com a potência e legitimidade de seus elementos originais. Assim, a questão de objetos como duplicatas, substitutos e representantes de um indivíduo era central para os egípcios, principalmente no contexto funerário, e devemos analisá-la para compreender melhor as ligações entre as esposas divinas e seus shabtis.

Segundo as noções de materialidade egípcia antiga, estátuas e estatuetas, imagens em relevos e/ou pintadas de indivíduos, divindades ou objetos eram consideradas todas como cópias do próprio ser ou coisa representados. As imagens e objetos eram portadores da identidade do que era retratado, e por isso poderiam ser feitas idealmente - por exemplo, em formatos de pessoas mais jovens e sem as deficiências que poderiam ter em vida -, bem como agiam como substitutos no pós-morte. Nesse sentido, a realidade física da representação era feita buscando a eficácia de se conceder o que era desejado por e ao seu possuidor (Meskell, 2004, p. 7). Nos shabtis, por exemplo, além das ferramentas agrícolas retratadas nas estatuetas, contamos também com os nomes, títulos, símbolos e 
Mare Nostrum, ano 2021, v. 12, n. 1 .

encantamentos para que os servidores obtivessem o máximo de eficiência em suas tarefas no lugar do morto.

Assim, levaremos em conta a presença, em essência, de um indivíduo em suas representações, cópias e/ou substitutos materiais, bem como a busca pela eficiência desses objetos em suas funções no pós-morte. Para isso, precisamos compreender como os egípcios antigos entendiam o caráter de substituto e cópia em sua cultura material, assim como a forma pela qual eles poderiam entender suas identidades e individualidades, as quais eram passadas aos seus objetos.

Para Meskell (2004, p. 119), o princípio de cópia era fundamental para os egípcios, principalmente no contexto funerário, no qual era esperado que o morto fosse não só retratado, mas também que fosse garantido que ele se manteria seguramente no Além - o que envolvia sua preservação física em diversos meios. A autora menciona o caso dos shabtis, que, como desenvolvido anteriormente, eram estatuetas que deveriam substituir o falecido nas tarefas agrárias no pós-morte. Esses servidores são apenas um dos exemplos de cópia e substituição na cultura material egípcia de um indivíduo: temos o próprio corpo mumificado, assim como outros elementos que constituíam sua essência enquanto pessoa (o seu $b a, k a^{11}$, sombra e nome). Todas essas características eram entendidas como sósias de um indivíduo, e praticamente toda a vida de uma pessoa (até depois de morta) era perpassada pela potência e presença de suas cópias e simulacros materiais (Meskell, 2004, p. 119).

Sobre a individualidade e identidade, é possível afirmar que os egípcios antigos entendiam por indivíduo um ser que possuía um conjunto de características que o tornava reconhecido socialmente e também distinto dos demais. Segundo Wendrich (2010, p. 200), a identidade egípcia era composta por mais do que características individuais: ela era contextual e socialmente definida por meio de relações familiares, histórias compartilhadas, idade, gênero, ocupações, etnia, riquezas, etc e ela poderia ser imposta e alterada ao longo de circunstâncias diversas. Individualidade e identidade egípcias devem ser compreendidas como um processo de negociação social, submetidas a fatores internos e externos e que pressupõem mudanças ao longo do tempo.

Nesse contexto, as concepções do pós-morte exerciam grande influência em suas constituições. A identidade dos falecidos era uma construção simbólica, assim como o

\footnotetext{
${ }^{11} \mathrm{O}$ ba (muitas vezes equivocadamente traduzido como "alma" no sentido cultural ocidental e cristão) era um aspecto do corpo obtido após a morte que possuía a forma de um pássaro com a cabeça de humano. Já o $k a$ era entendido como a "força vital" de cada indivíduo (Wendrich, 2010, p. 207-208).
} 
resultado de interação social, comunicação e negociação com os vivos e mortos, o que poderia incluir identidades individuais e coletivas. Sujeita a manipulação e diferentes percepções por outros indivíduos, a identidade egípcia era essencialmente criada e modificada, podendo ser até mesmo alvo de tentativas de destruição (Wendrich, 2010, p. 201).

Para os egípcios antigos, seu corpo mumificado, suas representações visuais e textuais e seu equipamento funerário poderiam ser entendidos, portanto, como substitutos, extensões e cópias materiais de sua individualidade e essência. Esses objetos retratavam os falecidos idealmente, da maneira convencionada como apropriada, mesmo que muitas vezes a realidade não correspondesse à representação (Meskell, 2004, p. 126127). Ademais, todos os seus símbolos e marcadores de status social eram retratados e ressaltados, tanto títulos como elementos ligados à realeza, divindades ou a um ofício exercido em vida. Assim, garantia-se a eficiência, em termos mágicos, para a completude física do falecido e para o que era esperado de se realizar e obter no pós-morte (Meskell, 2004, p. 130). Eram a materialidade e as noções de cópia, simulacro, substituição e identidade que possibilitavam o controle e redirecionamento potencial das diferentes trajetórias de um indivíduo egípcio na vida e na morte.

\section{A Análise dos Shabtis de Karomama G Merytmut, Qedmerut, Amenirdis e Shepenupet II}

A análise dos shabtis selecionados será dividida em três partes: a primeira focará sobre suas características gerais e a relação deles com o arcaísmo núbio; a segunda tratará sobre as inscrições textuais que neles se encontram; e a terceira, por fim, examinará os símbolos que foram visualmente retratados neles.

\subsection{Características Gerais e o Arcaísmo}

Ao examinarmos rapidamente os quatro shabtis, é possível notar que eles seguem as características básicas pressupostas dessas estatuetas: suas cores são primariamente azuis e pretas, conectando-as com as concepções de regeneração, com o mundo dos mortos e com os deuses Amon e Osíris. Elas seguem o estilo de servidor mumiforme ou contramestre (no caso da de Karomama G Merytmut) e elas portavam ou não ferramentas agrícolas - ou chicote, no caso dos contramestres. Aparte às características básicas, todos 
Mare Nostrum, ano 2021, v. 12, n. 1 .

eles portavam um uraeus ou um suporte para tal símbolo, o qual foi fragmentado ou quebrado - não sabemos se por algum indivíduo que teve contato com eles e/ou pela ação do tempo.

Neste momento, interessa-nos principalmente os dois shabtis das esposas divinas núbias, Amenirdis e Shepenupet II. Diferentemente das estatuetas de Karomama G Merytmut e Qedmerut, compostas em faiança azul no tamanho tradicional dos shabtis, os servidores de Amenirdis e Shepenupet II foram feitos em pedra negra escura, provavelmente serpentina, o que demonstra uma ligação com as ideias de eternidade e a garantia de sua durabilidade. O que nos chama atenção nessas duas estatuetas, além de seu material, tamanho e cor, são os sorrisos encontrados em suas faces e a inscrição do servidor de Amenirdis (uma versão do Capítulo 6 do Livro dos Mortos, datada da $13^{\mathrm{a}}$ dinastia), elementos esses baseados nos Reinos Médio e Novo e que estão relacionados ao movimento arcaizante estabelecido pelos núbios.

Devemos ampliar a discussão de arcaísmo egípcio para compreender as relações desses shabtis com esse movimento. Este, como já colocado, não foi um ineditismo por parte dos faraós núbios, ocorrendo em diferentes períodos históricos do Egito. Schneider (1977, p. 321) aponta que, antes dos núbios, nas $23^{\text {a }}$ e $24^{\text {a }}$ dinastias, ambas marcadas pela presença de faraós líbios, já havia shabtis com características arcaizantes. Dessa forma, não podemos considerar o arcaísmo núbio como o único momento de resgate de elementos artísticos egípcios, nem podemos considerar esse movimento de maneira uniforme para todo o Terceiro Período Intermediário. É preciso entendê-lo também do ponto de vista dos próprios núbios (Török, 1997, p. 190-191).

Muitos autores caracterizam estátuas e imagens dos faraós núbios na cultura material egípcia como excepcionais e muito específicas. A face redonda, nariz curto com amplas narinas, lábios carnudos e a pele negra eram alguns dos traços específicos atribuídos aos núbios. Entretanto, Török aponta que essas características já existiam na arte egípcia de períodos antigos, descartando a tendência de representação "realista" dos reis núbios como algo único na história do Egito, na medida em que, por exemplo, a própria representação da cor da pele negra já era anterior na iconografia egípcia (Török, 1997, p. 194).

Além disso, não podemos generalizar o arcaísmo da $25^{\text {a }}$ dinastia como apenas uma forma de legitimação por parte dos faraós núbios. Isso simplifica uma série de outros interesses por parte desses em relação ao seu controle sobre o Egito. Para Török (1997, p. 195), não é possível afirmar que o arcaísmo é somente busca por legitimação - o que 
implica em uma ideia de mascaramento por parte dos núbios como egípcios, e, dessa forma, negando ou subordinando suas identidades em relação a eles. Ao analisarmos atentamente a cultura material egípcia desse período, é possível encontrar nas representações da família real, e até mesmo nas das esposas divinas, elementos próprios da realeza núbia, como vestimentas, adornos e coroas, por exemplo. Assim, os núbios ressaltaram suas identidades na materialidade egípcia, um processo complexo que não deve ser submetido apenas a uma tentativa de legitimação.

Vale ressaltar que o arcaísmo sobre os shabtis das esposas divinas ocorre também para as estatuetas de outros grupos sociais. Servidores funerários em serpentina preta ou esverdeada foram feitos para os altos sacerdotes e também para a realeza egípcia da $25^{\mathrm{a}}$ dinastia (Schneider, 1977, p. 321). Por parte das esposas divinas, o uso de características arcaizantes em suas estatuetas estaria mais relacionado ao status e destaque de seu ofício, o qual se encontrava bem consolidado e com fortes influências políticas em Tebas, do que somente com uma forma de reforçar a legitimação dos reis núbios, já aceitos como governantes do Alto Egito pelo sacerdócio de Amon por meio da nomeação de Amenirdis como esposa divina.

\subsection{Títulos e Outras Inscrições}

Como colocado anteriormente, os shabtis podiam trazer inscrições de nomes e títulos de seu proprietário, o que nos permite conhecer o nome do indivíduo e pelo menos um de seus títulos - por vezes, até o nome de algum de seus parentes. Dado o tamanho pequeno dessas estatuetas e o espaço disponível para escrita, a escolha do título a ser inscrito não era neutra e, por isso, deveria priorizar alguns em detrimento de outros. A quantidade de títulos por indivíduos, principalmente os da realeza, poderia variar conforme status, cargos ocupados e status social e religioso. O faraó, por exemplo, possuía mais de um nome e titulatura que o ligavam à realeza e às diferentes divindades. Para Meffre (2018, p. 138), a escolha de um título a ser inscrito em um shabti muitas vezes pode nos surpreender, já que ela nem sempre corresponde ao que consideraríamos como o título mais importante de um indivíduo.

No caso dos shabtis selecionados das esposas divinas, isso é particularmente notável. Essas sacerdotisas eram esposas de Amon, o que implicava em pelo menos três títulos: Esposa Divina, Adoradora Divina e Mão do deus. Ademais, elas eram filhas do rei do Egito, possuindo também o status de realeza. Ambas as ligações das esposas 
divinas eram consideradas importantes e prestigiadas, dignas de serem mencionadas em suas estatuetas. Segundo Meffre (2018, p. 138), de maneira geral, é possível notar nos shabtis encontrados em Tebas uma preferência por algum título que o indivíduo possuísse e que fosse relacionado ao deus Amon, já que ele era a principal divindade na região e no contexto do Terceiro Período Intermediário ${ }^{12}$.

As quatro estatuetas funerárias que são objetos deste artigo fazem menção a Karomama G Merytmut, Qedmerut, Amenirdis e Shepenupet II como esposa divina ou adoradora divina, ressaltando, assim, sua ligação com seu marido secular. Nesse sentido, a prioridade de títulos voltados ao sacerdócio de Amon dialoga com a colocação de Meffre acima. No Terceiro Período Intermediário, o papel de Amon no contexto funerário cresce em detrimento do de Osíris, ainda que a função e importância do último não tenham sido eliminadas. Cria-se, nesse momento, uma ligação simbólica entre os shabtis e o deus tebano, não estando mais as estatuetas ligadas apenas a Osíris. Segundo Schneider (1977, p. 319-320), os processos de criação, aquisição e concessão de vida a esses servidores funerários deveriam passar pelo consentimento de Amon, não apenas no contexto simbólico, mas também no prático, haja vista o domínio do sacerdócio desse deus sobre boa parte dos ateliês de faiança e dos papeis do oráculo de Amon em conceder vida e capacitar os shabtis a realizar suas funções no Além. Assim, é possível pensarmos na prioridade dos títulos de Amon nos servidores funerários como um dos reflexos dessa mudança de concepção religiosa.

Entretanto, quando possível, essas sacerdotisas não deixaram de lado o registro de sua ligação com a realeza egípcia nas inscrições. No shabti de Qedmerut, por exemplo, ela se representa como Adoradora Divina e como Senhora das Duas Terras, título que faz referência ao papel do faraó enquanto rei do Alto e do Baixo Egito e que, por vezes, era utilizado por rainhas. Algo semelhante ocorre com o servidor funerário de Shepenupet II: um de seus títulos identificados é o de Filha do rei Piankhy. A comparação entre esses dois shabtis e os títulos representados nos leva a questionar as motivações das escolhas dos que fazem referência à realeza egípcia. Ayad (2009, p. 1) nos aponta que o título "filha do rei" era utilizado nos diversos relevos iconográficos das esposas divinas líbias,

\footnotetext{
${ }^{12}$ É necessário fazer algumas considerações quanto a essa preferência. Apesar de não possuirmos acesso a todos os shabtis de uma das quatro esposas divinas selecionadas neste artigo, para além da escolha que priorizava a ligação com Amon nas inscrições (como colocado por Meffre) devemos ter em mente o caráter formular de boa parte da produção material funerária egípcia. Essa dificuldade quanto ao acesso e incorporação de mais estatuetas servidoras de cada sacerdotisa para análise nos leva à reflexão quanto ao limite da agência por parte das inscrições em um quadro mais amplo e também sobre a relevância desses títulos na maior parte dos shabtis que possuímos hoje.
} 
núbias e saítas. Elas costumavam se apresentar nas fontes tanto como esposas de Amon como filhas do faraó e, quase invariavelmente, esse último título antecedia seus nomes envoltos de um cartucho (outra prerrogativa faraônica/real).

No caso do servidor de Shepenupet II, a ligação de títulos da realeza egípcia com a interpretação tradicional do arcaísmo da $25^{\text {a }}$ dinastia como forma de legitimação do reinado núbio sobre o Egito perde um pouco sua força, uma vez que eles são encontrados também, por exemplo, na estatueta de Qedmerut, uma sacerdotisa de uma dinastia anterior. Ou seja, esse tipo de título não era uma característica incomum nos shabtis das esposas divinas. Além disso, se compreendermos o uso de um título real na estatueta de Shepenupet II apenas como uma prática de legitimação faraônica nós retiramos as agências das esposas divinas quanto às escolhas sobre quais partes de suas identidades seriam retratadas, e as implicações que elas teriam do ponto de vista dessas sacerdotisas.

Como colocado anteriormente, as esposas divinas líbias e núbias foram retratadas em status e funções semelhantes às dos faraós em relevos iconográficos na região de Tebas (Ayad, 2009, passim); fato que é resultado de uma culminação de poder social, religioso e político adquirido ao longo do tempo por essas sacerdotisas. Se pensarmos na constituição de seus status no contexto funerário e o que era desejado por elas para ser retratado em seus substitutos nos trabalhos agrícolas no pós-morte, inserir seus títulos de identificação tanto com o deus Amon como com a realeza egípcia aumentava ainda mais suas agências e status enquanto indivíduos - o que era desejável de se manter e propagar no Além. Entender os shabtis como substitutos diretos, ou como apenas objetos caracterizados com atributos de seu proprietário, nos leva ao mesmo caminho de sua compreensão como extensões e/ou cópias do falecido. Nesse sentido, as reflexões sobre a materialidade egípcia nos auxiliam no entendimento dessas estatuetas como agentes e representantes da identidade e essência de uma pessoa; no caso, de mulheres que usufruíram diretamente de elementos simbólicos reais, sacerdotais e, em certa extensão, divinos.

\subsection{O Uso do Uraeus}

Dentre os signos visuais que acompanham os shabtis selecionados, aparte dos tradicionais instrumentos relacionados aos trabalhos agrícolas desses servidores, notamos em todas as estatuetas a presença de um uraeus ou um espaço reservado para ele. Como colocado anteriormente, esse símbolo, que poderia consistir em uma cobra e/ou uma 
cobra junto a um abutre, aparecia em adornos e coroas em sua parte frontal e era uma insígnia faraônica, por vezes portada por algumas rainhas na cultura material egípcia.

O fato de as esposas divinas utilizarem esse símbolo em seus shabtis, por serem também princesas, não parece tão estranho. Entretanto, esse uso possui algumas implicações relacionadas ao status que essas mulheres foram desenvolvendo desde o surgimento do ofício até o período da $25^{\mathrm{a}}$ dinastia. A presença do uraeus, mais comum em shabtis de reis, não é esporádica nos servidores funerários dessas sacerdotisas. Segundo Gombert-Meurice e Payraudeau (2018, p. 337), todos os exemplares de shabtis de Amenirdis que conhecemos hoje possuem o uraeus. Ademais, por estar presente também nas estatuetas de Karomama G Merytmut e Qedmerut, ambas sacerdotisas líbias, não podemos afirmar que seu uso é exclusivo da política arcaizante núbia. Para Meffre (2018, p. 140), os uraeus configuram esses shabtis como substitutos diretos e feitos de acordo com a imagem desejada de se manter por essas sacerdotisas no pós-morte.

Podemos retirar dessa apropriação simbólica pelo menos duas coisas: a primeira é a de que as esposas divinas procuraram retratar seus status tanto de sacerdotisas como de princesas em seus shabtis, tanto visual como textualmente. Isso nos leva a uma reflexão sobre o uso dos servidores funerários também como um meio de reforço e manutenção mágica das identidades dessas mulheres, uma maneira de dotar seus substitutos no trabalho agrícola com seus status e, assim, também perpetuar por meio a forma como elas desejavam ser reconhecidas no pós-morte. A partir dessa ideia, partimos para uma segunda reflexão: os shabtis analisados das esposas divinas, então, podem ser entendidos menos como substitutos descolados da identidade de suas possuidoras, como um servidor anônimo, e mais como trabalhadores atrelados à imagem de suas proprietárias e seus status, garantindo física e magicamente seus prolongamentos para o mundo pós-morte.

\section{Considerações Finais}

Não podemos considerar os shabtis das esposas divinas analisados como servidores despersonalizados. Seus títulos e símbolos os conectam diretamente com suas proprietárias. Para além de uma discussão sobre o caráter dessa substituição, é essencial notar que as escolhas sobre o que foi retratado nas estatuetas não eram neutras e, além de estarem ligadas à materialidade egípcia em relação ao pós-morte, elas possuem diferentes agências das esposas divinas imbuídas em si. Ao se retratarem como esposas e adoradoras 
de Amon, filhas do rei e com a presença de uraeus como adorno, essas mulheres ressaltam suas funções em vida - desejáveis de serem perpetuadas ao Além -, enquanto sacerdotisas de Amon e princesas. As características materiais e simbólicas de seus servidores, principalmente os das esposas divinas núbias, não devem ser compreendidas como reflexos de um arcaísmo, seja líbio ou núbio, que visava apenas uma legitimação dos faraós enquanto governantes do Egito.

Os shabtis das esposas divinas são muito importantes para entendermos o ofício em sua constituição e atuações, possibilitando até mesmo o nosso conhecimento sobre a existência de esposas divinas que não são atestadas por meio de outras fontes. Além de serem produtos da materialidade funerária egípcia, esses servidores também são frutos de representação de status e identidades de suas proprietárias, os quais abrangiam os âmbitos sacerdotal e real. A retomada de características arcaizantes soma-se a essas intenções e agências, que demonstram o crescente poder obtidos por essas mulheres nas esferas religiosa, funerária, social e política na região de Tebas.

Recebido: $24 / 08 / 2020$

Aprovado: 09/10/2020 


\section{REFERÊNCIAS BIBLIOGRÁFICAS}

Agut, D. \& Moreno-García, J. C. (2016). L’Égypte des pharaons: De Narmer à Dioclétien (3150 av. J.-C.-284 apr. J.C.). Éditions Belin.

Ayad, M. (2009). God's Wife, God's Servant: The God's Wife of Amun (c. 740-525 BC). Routledge.

Baines, J. (2007). Visual and written culture in ancient Egypt. Oxford University Press.

Bovot, J. (2003). Les Serviteurs funéraires royaux et princiers de l'Ancienne Égypte. Éditions de la Réunion des musées nationaux.

Bunson, M. (2012). Encyclopedia of Ancient Egypt. Facts On File.

Coulon, L. (2018). Les divines adoratrices à Thèbes: La construction d'une dynastie. In Frédéric Payraudeau \& Florence Gombert-Meurice. Servir les dieux d'Égypte: Divines adoratrices, chanteuses et prêtes d'Amon à Thèbes (p. 270-281). Somogy Éditions d'Art.

Doxey, D. (2001). Names. In Donald B. Redford, D. (Org.), The Oxford Encyclopedia of Ancient Egypt, vol. II (p. 490-492). Oxford University Press.

Gama, C. (2008) Os servidores funerários da coleção egípcia do Museu Nacional: Catálogo e Interpretação. Dissertação (Mestrado em Arqueologia), Museu Nacional, Universidade Federal do Rio de Janeiro.

Gell, A. (2018). Arte e Agência. Ubu.

Gombert-Meurice, F. \& Payraudeau, F. (Orgs.). (2018). Servir les dieux d'Égypte: Divines adoratrices, chanteuses et prêtres d'Amon à Thèbes. Somogy Éditions D'Art.

Gosselin, L. (2007). Les Divines Épouses d'Amon dans l'Égypte de la XIXème à la XXIème dynastie. Cybele.

Kahl, J. (2010) Archaism. In Willeke Wendrich. UCLA Encyclopedia of Egyptology (pp. $1-9)$.

Meffre, R. (2018). Les serviteurs funéraires thébains de la Troisième Période intermédiaire. In Frédéric Payraudeau \& Florence Gombert-Meurice. Servir les dieux d'Égypte: Divines adoratrices, chanteuses et prêtes d'Amon à Thèbes (p. 134141). Somogy Éditions d'Art.

Meskell, L. (2004). Objects Worlds in Ancient Egypt: Material Biographies Past and Present. Berg.

Nicholson, P. T. (2001). Faience. In Donald B. Redford (org.). The Oxford Encyclopedia of Ancient Egypt, vol. I (p. 491-496). Oxford University Press. 
Nicholson, P. T. (2005). Faïence technology and production. In Kathryn A. Bard \& Steven B. Shubert (Orgs.). Encyclopedia of the Archaeology of Ancient Egypt (p. 352-354). Routledge Taylor \& Francis e-Library.

Pinch, G. (2002). Egyptian Mythology: A guide to the gods, goddesses and traditions of ancient Egypt. Oxford University Press.

Robins, G. (2001). Color Symbolism. In Donald B. Redford (Org.). The Oxford Encyclopedia of Ancient Egypt, vol. I (pp. 291-294). Oxford University Press.

Schneider, H. B. (1977). Shabtis: An Introduction to the history of ancient Egyptian funerary statuettes with a catalogue of the collection of shabtis in the National Museum of Antiquities at Leiden, vol. II. Rijksmuseum van Oudheden.

Shaw, I. (Org.). (2000). The Oxford History of Ancient Egypt. Oxford University Press.

Taylor, J. (2000). The Third Intermediate Period (1069-664 BC). In Ian Shaw. (Org.). The Oxford History of Ancient Egypt (p. 324-363). Oxford University Press.

Török, L. (1997). The Kingdom of Kush: Handbook of the Napatan-Meroitic Civilization. Brill.

Wendrich, W. (2010). Identity and Personhood. In Willeke Wendrich (ed.). Egyptian Archeology (pp. 200-219). Wiley-Backwell. 
Mare Nostrum, ano 2021, v. 12, n. 1.

\section{MATERIALITY AND IDENTITY: \\ THE SHABTIS OF THE GOD's WiVES OF AMUN}

\section{ABSTRACT}

The priestesses known as the god's wives of Amun were quite important during some periods of the Egyptian history. They had various shabtis, statuettes that replaced them in the agrarian works in the afterlife. Some of them, belonging to foreign domination periods of Egypt, had characteristics from the archaism - understood as a way of legitimation of the foreign kings. Through the concepts of materiality and identity, this article analyzes four shabtis of god's wives from the XXII and XXV dynasties to understand how they disconnect from a simple legitimation process and how they are important to comprehend the status of these priestesses.

\section{KEYWORDS}

God's wife of Amun; shabti; funerary server; archaism; materiality. 